\title{
Comment
}

\section{Our tools and our solutions}

Russ Ackoff and others have repeatedly criticized our profession as moving from a tool-using discipline to a tool-producing discipline. Tool users would tend to concentrate on good solutions in real-world situations, while tool producers may be satisfied by having powerful tools.

As a matter of fact, we in the OR community concentrate our endeavours on our tools, which are, by and large, considered as a subset of mathematics, i.e. theorems, proofs and algorithms; and our tools are extremely powerful! Many of them originate from the fruitful decade of the 1950s and have been remarkably improved since. Our profession can, therefore, be proud of its tools. Our monographs and journals are an indicator of thls pride, and the successful tool-making justifies the pride.

However, there seems to be a lack of pride in the solutions provided by our profession, i.e. in the contributions to make our world a better world. In order to make the difference clear between tools and solutions, let us consider some analogies:

- Take an architect: What do we think of him if he only presents his pride in his tools, i.e. his drawing board, his CAD system, his model workshop? Would we not expect to see his solutions, i.e. his buildings, at least in graphs and plctures?

- Take a craftsman: How would we judge his abllities if he only spoke of his tools and let us have a look into his toolkit? Should we not prefer to see his solutions, I.e. his products?
- Take a lawyer: How should we value his competence if he only spoke about his tools, i.e. his professional library, his access to databases, his computer-aided text production? Should we not prefer to see his solutions, i.e. hls success in trials, his drafts of contracts and statutes?

Should be OR profession not more deeply emphasize its pride in the solutions? Miceal Ross reports about one of Churchman's solutions in a recent brochure, $O R$ in Ireland (p. 102f). His OR team was called to a high-rise tower where, "in spite of the efforts of the architects and engineers, there were innumerable complaints about the time taken by the elevators to reach the clients. The ingenious solution the OR team proposed was to install mirrors near the push buttons, since they observed that fixing one's appearance reduced one's perception of the time taken for the elevator to arrive". Is that not a great solution?

Imagine our profession had as many solutionoriented journals as it has technical, mainly tool-oriented journa/s! Imagine the vast readership - neither a thinker nor a doer could afford to miss any issue because he might miss a solution to one of his problems, even if the solution may not be an easy one and might require quite an ambitious analysis.

It seems as if the image of our profession is characterized by our tools. Would it not be worth the effort to widen the image of OR by a strong solutionoriented component?

HEINER MÜLLER-MERBACH

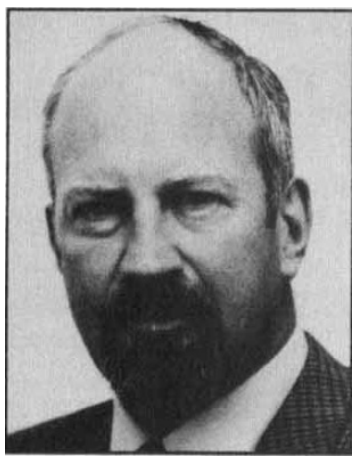

Professor HEINER MÜLLER-MERBACH is a former President of the International Federation of Operational Research Societies. He was recently elected a Companion of $O R$ by the OR Society. 